УДК 631.61(083.74)

\title{
ПРИНЦИПЫ СОЗДАНИЯ СИСТЕМЫ РЕАЛИЗАЦИИ ГОСУДАРСТВЕННОЙ ПОЛИТИКИ РАЗВИТИЯ МЕЛИОРАТИВНОГО КОМПЛЕКСА РОССИИ
}

\author{
(C) 2012 г. Е. А. Васильева*, А. А. Петлеванный** \\ * Территориальное управление Финансово-бюджетного надзора \\ в Ростовской области, г. Ростов-на-Дону \\ ** Российский научно-исследовательский институт проблем мелиорации, \\ 2. Новочеркасск
}

Предложена система программных мероприятий и ресурсного обеспечения для развития мелиоративного комплекса, системы планирования восстановления оросительных систем на региональном и муниципальном уровнях, механизм реализации программь развития мелиоративной отрасли АПК.

Ключевые слова: мелиоративный фонд; орошаемые земли; осушаемые земли; мелиорируемые земли; урожсайность; сельхозпроизводство; индикативное планирование; иелевые показатели.

The system of program activities and resource support for the development of the land reclamation complex, working out the restoration activities for the irrigation systems on the regional and municipal levels, the mechanism of implementation of the development programs for the land reclamation industry of the agroindustrial complex are presented in the article.

Key words: land reclamation fund; irrigated lands; drained lands; reclaimed lands; crop yields; agricultural production; indicative planning; the targets.

Резкое изменение в последние десятилетия экономической ситуации в стране, обусловившее кризисные явления в агропромышленном комплексе, привело к значительному сокращению сельскохозяйственных площадей. Наряду с общими причинами макроэкономического порядка, которые привели к такой ситуации, следует указать и на специфические, свойственные только мелиорации. Прежде всего, это: ориентация отрасли на централизованное бюджетное финансирование; технологические и правовые ограничения, препятствующие налаживанию коммерческих отношений на рынке услуг по водопользованию землепользователей, создающие предпосылки к потере управления объектами отрасли; значительная капиталоемкость мероприятий по адаптации отрасли к условиям рынка; экологические проблемы, обусловленные ведением орошаемого земледелия.
Принимая во внимание то, что факторы развития мелиорации в текущий период труднопрогнозируемы и зачастую носят вероятностный характер, перспективным направлением оценки их влияния представляется использование апробированного в АПК сценарного подхода $[1 ; 2]$, позволяющего имитировать различные варианты планов развития и принимать решения, направленные на достижение целей мелиоративного развития сельскохозяйственных территорий. Таким образом, в качестве методической основы формирования и анализа сценариев восстановления и реконструкции оросительных систем предлагается использовать аппарат планирования, получаемый в результате адаптации к функциональной системе границ, обусловленных переходом АПК к индикативному планированию.

Важным требованием к разрабатываемым моделям планирования является учет 
опыта современного реформирования сельского хозяйства и, прежде всего, учет трансформационных изменений сельскохозяйственных (в т. ч. земельных) отношений. Анализ работ отечественных агроэкономических школ позволяет констатировать тот факт, что кардинальное негативное воздействие на ход реформ оказало принятие в качестве базовой модели реформирования либеральной теории рыночной экономики.

Применение апробированного в сельском хозяйстве сценарного подхода, являющегося основой экономического индикативного планирования, предполагает ориентацию на методы анализа вариантов реконструкции объектов мелиорации в рамках федеральных «Сценариев для АПК», национальных проектов, ведомственных и региональных целевых программ, программ и планов муниципального и хозяйственного уровней.

В качестве субъектов планирования выделяются:

- объекты первого типа - главные распорядители выделяемых средств федерального бюджета (агентства и службы Минсельхоза России); реализация планируемых мелиоративных мероприятий обеспечивается за счет целевых средств бюджета;

- объекты второго типа - администрации регионов и предприятий-собственников; реализация мероприятий обеспечивается при включении объектов в целевые региональные программы за счет части средств на выполнение программ (субсидий федерального бюджета, региональных бюджетов, средств кредитной поддержки «Россельхозбанка», собственных средств хозяйств);

- объекты третьего типа - администрации регионов и муниципальных образований, собственники участков поливной сети (крестьянские (фермерские) хозяйства и сельскохозяйственные потребительские кооперативы); реализация восстановительных мероприятий обеспечивается путем включения объектов в ежегодные планы производственно-финансовой деятельности предприятий, в бизнес-планы товаропроизводителей, в среднесрочные и годовые планы социальноэкономического развития сельских территорий районов; финансирование мероприятий осуществляется из федеральных средств на развитие малых форм хозяйствования (про- ект «Развитие АПК»), из средств предприятий, из бюджетов муниципальных образований (Закон о местном самоуправлении) и из нормируемых Законом налоговых поступлений (земельного налога, налога на имущество, налога с физических лиц, единого сельскохозяйственного налога и др.).

Система непосредственного планирования на региональном уровне включает следующие блоки (рис. 1):

1. Свод показателей бизнес-планов товаропроизводителей на муниципальном и региональном уровнях; по результатам этого этапа проводится увязка финансовых и других ресурсов с источниками их формирования, определяются валовые показатели производства, выделяются объемы производства отдельных видов сельскохозяйственной продукции для компенсации дефицитов путем внедрения мелиоративных технологий; при проведении расчетов используются показатели потребности населения в продуктах питания (по медицинским нормам) и уровни их удовлетворения (по статистическим данным), статистические показатели дефицитности базы кормопроизводства и другие.

2. Формирование в рамках выделенных сценариев состава плановых объектов реконструкции, с учетом уровней покрытия установленных дефицитов сельхозпродукции при вводе их в эксплуатацию.

Содержательная постановка плановых задач формулируется следующим образом: определить набор объектов реконструкции, обеспечивающий получение максимума суммы ЧДД или бюджетных поступлений от хозяйств и удовлетворяющий требованиям выпуска необходимых объемов продукции; в рамках оптимистического сценария в задачи вводится условие покрытия выделяемых бюджетных средств приростом налоговых поступлений.

3. Уточнение состава объектов реконструкции на этапе включения сценариев и планов мелиоративных мероприятий в региональные программы социально-экономического развития сельских территорий. На этом этапе оцениваются структуры вложений на восстановление и реконструкцию объектов; в случаях преобладания вложений из бюджетных источников и регионального фонда мелиорации земель возможны корректировки 


\section{1} сти пакета бизнес-планов хозяйств для региональных бюджетов (по показателям экономической и социально-экологической значимости проектов восстановления внутрихозяйственной сети).

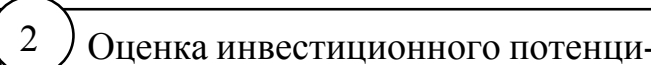
ала развития мелиорации по индикативным показателям проектов сценариев федерального уровня.

\section{$\checkmark>$}

3 Обоснование прогнозируемых объемов бюджетного финансирования мелиоративных мероприятий за счет средств на реализацию региональных программ развития АПК и целевых средств на реализацию федеральных программ восстановления почвенного плодородия.

(4)

4 Разработка институциональных мер по повышению доступности кредитов для хозяйств, по формированию регионального мелиоративного фонда и организационноэкономических механизмов стимулирования развития мелиорации и др.

\section{0}

5 Систематизация и свод бизнес-планов хозяйств (суммарная площадь орошения, специализация, валовая и товарная продукция, вклады в покрытие дефицитов по направлениям использования продукции, заявленная структура вложений, источники, сводный финансовый профиль бизнес-планов).

6 Систематизация материалов паспортизации технического состояния межхозяйствен-

ных элементов оросительных систем (состав и размещение объектов, экономически обоснованная очередность реконструкции, необходимые объемы).

7

Оценка перспектив реализации и выбор возможных сценариев финансирования: опти-

мистического, пессимистического, инерционного, инновационного и др. Распределение источников и условий финансирования в разрезе принятых для анализа.

82

8 Формирование предварительного списка объектов реконструкции на среднесрочную (3-5 лет) перспективу по результатам сопоставления требуемых и прогнозируемых средств на проведение реконструкции.

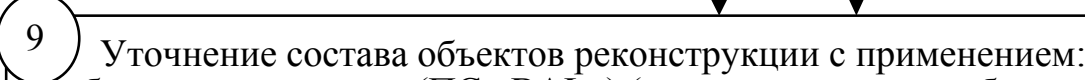

балансового метода (ПС «BAL») (определение масштабов и очередности восстановления массивов на среднесрочную перспективу);

- оптимизация моделей (ПС «ОРТ»)(обоснование краткосрочных годовых планов восстановления оросительной сети в хозяйствах с учетом лимитов водопотребления, технологических, водоохранных и других ограничений).

\section{0}

Корректировка планов восстановления мелиоративных объектов в увязке с реализацией региональных программ прогнозируемой динамикой внедрения организационноэкономических механизмов стимулирования развития орошения.

Рис. 1. Система планирования восстановления оросительных систем на региональном и муниципальном уровнях 
планов по мере внедрения в хозяйственную практику организационно-экономического механизма, построенного на принципе соблюдения динамического баланса интересов государства и хозяйств при проведении мелиоративных мероприятий иработ. В качестве регуляторов баланса экономических интересов сторон могут при этом использоваться:

- региональные стимулирующие постановления в отношении хозяйств, приобретающих современную поливную технику и занимающихся комплексной реконструкцией мелиоративных систем (меры по планомерному снижению налогов, увеличению объемов бюджетного обслуживания коммерческих кредитов, по увеличению государственных субсидий);

- договорные обязательства хозяйств с государственными органами, имеющие целью стимулирование хозяйств на поддержание эксплуатационной готовности внутрихозяйственных систем и увеличение поставок продукции в государственные продовольственные фонды, увеличение налоговых поступлений в бюджеты за счет роста объемов реализации продукции мелиорированных угодий;

- санкции государства за нарушение хозяйствами договорных обязательств путем снижения объемов субсидирования, лишения права льготного кредитования затрат на мелиоративные мероприятия и приобретение материально-технических ресурсов.

Включение планов мелиоративных мероприятий в региональные программы развития сельских территорий может быть обеспечено путем придания планам статуса обязательных материалов в составе программ.

Переход к индикативному планированию мелиорации, интегрирующему инвестиционные возможности названных субъектов планирования и государственных средств управления экономикой, сопряжен с совершенствованием методов подготовки плановой документации на сложившихся уровнях управления развитием сельских территорий. На федеральном уровне предлагаемые дополнения к действующим методическим рекомендациям по формированию ведомственных целевых программ (ВЦП) направлены на повышение обоснованности планов реконструкции объектов первого типа. С этой це- лью в процессе разработки проектов целевых программ помимо заявок региональных органов, формируемых по результатам паспортизации технического и мелиоративного состояния объектов, необходимо использовать дополнительные материалы, подтверждающие экономическую и социально-экологическую значимость каждого включаемого в ВЦП объекта. К их числу, прежде всего, относятся материалы по продуктивности обслуживаемых объектом орошаемых площадей (валовые показатели производства сельскохозяйственной продукции, направления ее использования и вклады в покрытие дефицитов по указанным направлениям, эффективность в сравнении с богарным растениеводством, социальный эффект в увеличении занятости и платежеспособности населения и другие) [3].

Выбор показателей эффективности восстановления и развития мелиоративных объектов, используемых в ходе формирования региональных планов (этапы 8 и 9, рис. 1), в настоящем исследовании основывался на результатах анализа литературных источников и полученных материалах моделирования финансовых потоков. Литературные источники в качестве основных показателей эффективности инвестиционных проектов рассматривают показатели чистой текущей стоимости, индекса доходности, внутренней нормы доходности, срока окупаемости [1-3].

Бюджетный эффект мероприятий, включаемых в региональные программы и проекты реконструкции внутрихозяйственных систем и межхозяйственных объектов, предлагается оценивать по следующим показателям:

- дисконтированному значению сальдо поступлений и выплат из федерального и региональных бюджетов за плановый горизонт;

- сроку окупаемости бюджетных средств (периоду от начала финансирования до шага расчета, когда суммы дисконтированных поступлений и выплат примут одинаковые значения);

- сумме налоговых поступлений за период окупаемости бюджетных средств;

- сумме налоговых поступлений на единицу инвестиционных затрат государства.

Процессы среднесрочного и годового регионального планирования предполагаются информационно и функционально взаимос- 
вязанными, при этом годовое планирование рассматривается как средство реализации среднесрочного плана. В отличие от среднесрочного планирования, оперирующего агрегированными объектами (площадями восстанавливаемых систем, структурами севооборотов, общими объемами выпуска продукции) при годовом планировании в качестве объектов рассматриваются внутрихозяйственные системы конкретных хозяйствующих субъектов. В связи с этим корректируется состав и детальность варьируемых компонентов плановой среды. В их состав включаются:

- своды бизнес-планов хозяйств (блок 5, рис. 1), определяющие полученные хозяйствами оценки целесообразности внедрения инновационных мелиоративных способов сельскохозяйственного производства, заяв- ленные объемы и структуры инвестиционных ресурсов, включая средства государственной поддержки;

- текущие показатели ввода в эксплуатацию мелиоративных объектов, показатели технического и мелиоративного состояния нуждающихся в реконструкции внутрихозяйственных систем;

- показатели динамики совершенствования организационной структуры и правового режима систем;

- показатели платежеспособности и финансовой устойчивости хозяйствующих субъектов.

Укрупненная имитационная схема разработки годовых региональных планов приведена на рис. 2.

Сельскохозяйственное производство на

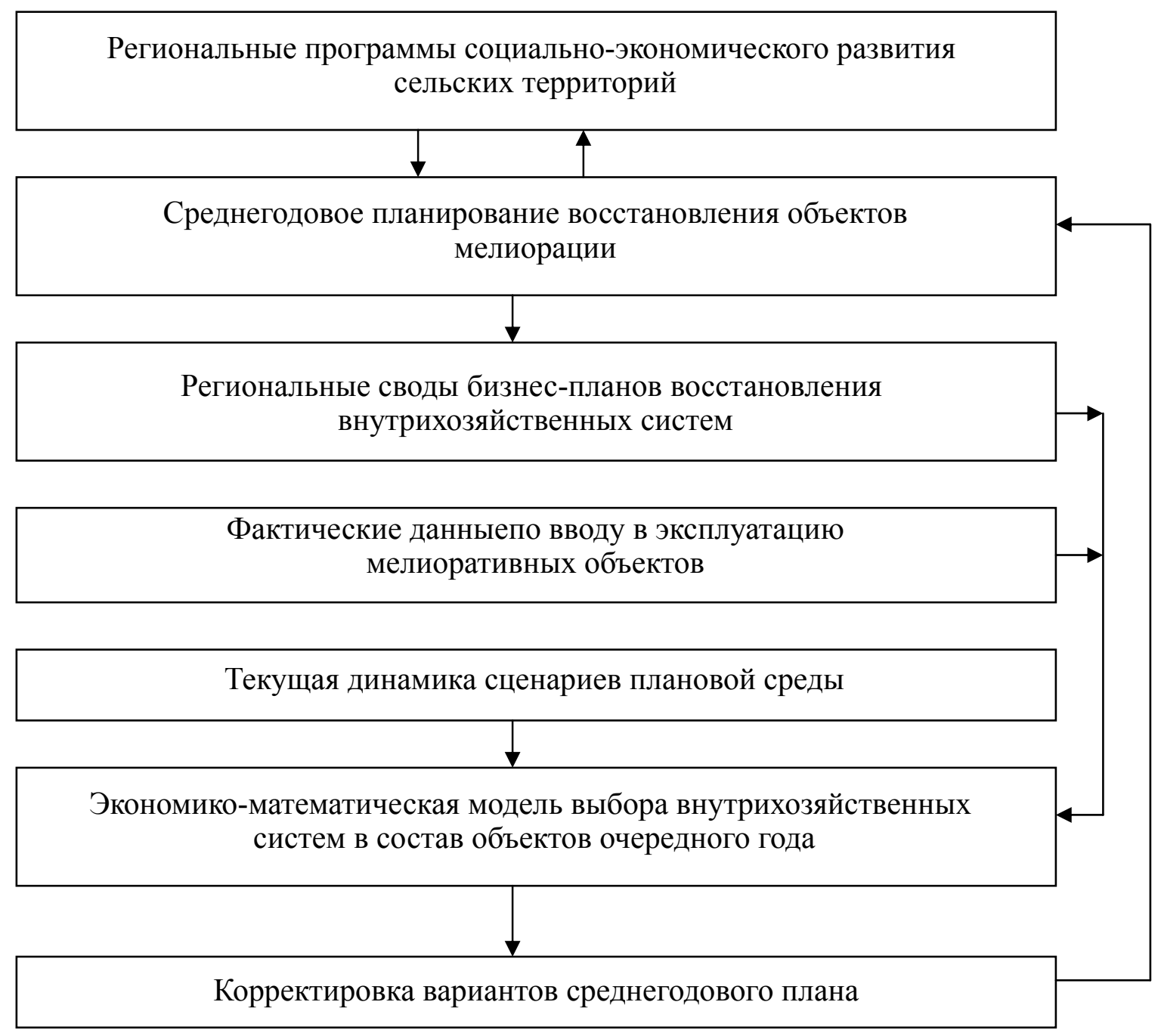

Рис. 2. Укрупненная имитационная схема разработки годовых региональных планов восстановления внутрихозяйственных оросительных систем 
орошаемых землях развивается за счет рыночных и внерыночных источников финансирования. Задача определения объемов общего финансирования для реконструкции и развития оросительной сети сводится к обоснованию потребности предприятий в финансовых средствах из внешних источников с учетом поступлений от собственной хозяйственной деятельности. При этом возникают вопросы обоснования объемов средств из планируемых источников и их сочетаний, таких, например, как: государственные льготные кредиты и прибыль хозяйств, кредиты коммерческих банков и средства от выпуска акций и др.

На фоне сохраняющейся тенденции к увеличению числа собственников орошаемых земель проблема при выборе источников и объемов финансирования с учетом требования баланса интересов финансируемых сторон, гарантий возврата вложений и других приобретает многовариантный и, зачастую, вероятностный характер. Для реализации этой проблемы планируется использовать сценарные оптимизационные подходы.

Для планирования развития межрегиональных объектов государственной собственности (магистральных каналов, гидроузлов и др.) в систему индикативного планирования необходимо внести корректировки, касающиеся содержания гипотез и концепций. В них должны найти отражение материалы, содержащиеся в схемах комплексного использования водных ресурсов бассейнов рек и регионов, и прежде всего - данные по водохозяйственной обстановке в створах анализируемых водозаборов.

Переход к индикативному планированию мелиорации, интегрирующему инвестиционные возможности названных субъектов планирования и государственных средств Поступила в редакциюю управления экономикой, сопряжен с совершенствованием методов подготовки плановой документации на сложившихся уровнях управления развитием сельских территорий. На федеральном уровне предлагаемые дополнения к действующим методическим рекомендациям по формированию ведомственных целевых программ (ВЦП) направлены на повышение обоснованности планов реконструкции объектов первого типа. С этой целью в процессе разработки проектов целевых программ помимо заявок региональных органов, формируемых по результатам паспортизации технического и мелиоративного состояния объектов, необходимо использовать дополнительные материалы, подтверждающие экономическую и социально-экологическую значимость каждого включаемого в ВЦП объекта. Состав включаемых в ВЦП объектов федеральной собственности устанавливается путем ранжирования показателей эффективности обслуживаемых ими площадей.

\section{Литература}

1. Гарькавый В. В., Гусева Н. Н. Планирование в предприятиях - неотъемлемая составляющая планирования. // Модели индикативного планирования социально-экономического развития сельских территорий: материалы Междунар. науч.-практ. конф., г. Ростов-на-Дону, 25-26 апреля 2006 г. - Ростов н/Д: ВНИИЭиН, РГЭУ «РИНХ», 2006.

2. Кузнецов В. В., Гарькавый В. В. Система экономического планирования развития АПК на региональном уровне. // АПК. Поиск. Решения. Опыт. - 2002. - №5.

3. Региональная экономика: проблемы, стратегия АПК. / Под. ред. В. В. Кузнецова. — Ростов н/Д: ВНИИЭиМ, 1998.

16 июня 2012 г. 


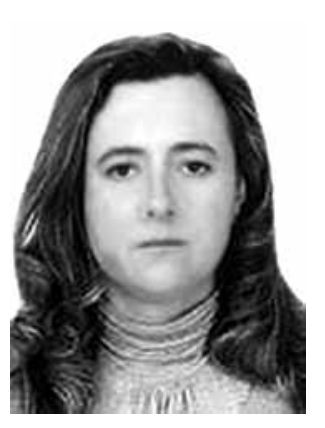

Елена Анатольевна Васильева - кандидат технических наук, сотрудник Территориального управления Финансовобюджетного надзора в Ростовской области.

Elena Anatolievna Vasilyeva - Ph.D., Candidate of Technics, official at the Rostov Region's Territorial Administration for the Financial and Budget Oversight.

346400 , г. Новочеркасск, ул. Ященко, 2-д

2-d Yashchenko st., 346400, Novocherkassk, Rostov reg., Russia

Тел.: +7 (928) 188-74-76; rosniipm@yandex.ru

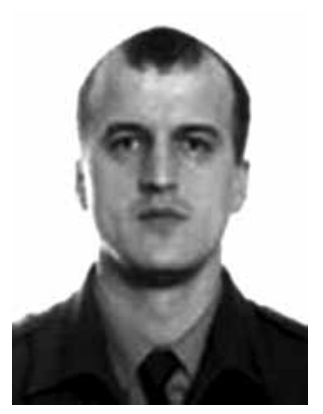

Алексей Александрович Петлеваный - соискатель Российского научно-исследовательского института проблем мелиорации (г. Новочеркасск).

Aleksey Aleksandrovich Petlevanny - competitor for the Candidate's degree at the Russian Research Institute for the Problems of Land Reclamation (Novocherkassk).

346421, г. Новочеркасск, Баклановский пр-т, 190

190 Baklanovskiy av., 346421, Novocherkassk, Rostov reg., Russia

Тел.: +7 (8635) 26-65-00; факс: +7 (8635) 26-82-22; e-mail: rosniipm@yandex.ru 